\title{
PJS, a novel isocoumarin with hexahydropyrimidine ring from Bacillus subtilis PJS
}

\author{
Shao-Wei Liu ${ }^{1}$, Jing Jin ${ }^{1}$, Chuan Chen ${ }^{1}$, Jia-Meng Liu ${ }^{1}$, Jing-Yan Li $^{1}$, Fei-Fei Wang ${ }^{1}$, Zhong-Ke Jiang ${ }^{1}$, \\ Ji-Hong $\mathrm{Hu}^{2}$, Zhen-Xiang $\mathrm{Gao}^{2}$, Fen $\mathrm{Yao}^{3}$, Xue-Fu You ${ }^{1}$, Shu-Yi $\mathrm{Si}^{1}$ and Cheng-Hang Sun ${ }^{1}$
}

The Journal of Antibiotics (2013) 66, 281-284; doi:10.1038/ja.2012.118; published online 23 January 2013

Keywords: amicoumacins; Bacillus subtilis; isocoumarin; PJS; structural elucidation

Amicoumacin group of antibiotics, such as baciphelacin, ${ }^{1}$ amicoumacins, ${ }^{2}$ AI-77s, ${ }^{3}$ xenocoumacins, ${ }^{4}$ Y-05460M-A, ${ }^{5}$ PM94128, ${ }^{6}$ Sg17-1-4, ${ }^{7}$ bacilosarcins $\mathrm{A}, \mathrm{B}^{8}$ and lipoamicoumacins A-D, ${ }^{9}$ is a small family of isocoumarin, which possesses the common chromophore, 3, 4-dihydro-8-hydroxyisocoumarin. Most members of amicoumacin group of antibiotics are produced by the genus Bacillus and exhibit various important bioactivities. The chromophore shows specific UV absorbance at 247 and $314 \mathrm{~nm}$ in methanol. Thus, a project based on HPLC-diode array screening and HPLC-MS dereplication was carried out to find new amicoumacin analogues from the secondary metabolites of Bacillus spp. As a result, PJS (1), a new isocoumarin antibiotic was discovered from the fermentation broth of Bacillus subtilis PJS. In this study, we wish to report the fermentation, isolation, physico-chemical properties, structural elucidation and biological activities of (1) (Figure 1).

The producing strain Bacillus subtilis PJS was isolated from the leaf of an unidentified plant collected at Luopu county, Hetian area, Xinjiang Province, People's Republic of China. On the basis of analysis of $16 \mathrm{~S}$ rRNA, it was identified as Bacillus subtilis subsp. inaquosorum. A stock culture of the strain Bacillus subtilis PJS was maintained on modified Gause's no. 1 agar slant consisting of soluble starch (Beijing Qi Te Xin Chemical Co. Ltd. China) $20.0 \mathrm{~g}, \mathrm{NaCl}$ 50.0 g, $\mathrm{K}_{2} \mathrm{HPO}_{4} 0.5 \mathrm{~g}, \mathrm{KNO}_{3} 1.0 \mathrm{~g}, \mathrm{MgSO}_{4} 1.0 \mathrm{~g}, \mathrm{FeSO}_{4} 0.02 \mathrm{~g}$, glucose $1.0 \mathrm{~g}$, peptone $0.5 \mathrm{~g}$, tryptone $0.3 \mathrm{~g}$ and agar $20.0 \mathrm{~g}$ in 1.01 distilled water ( $\mathrm{pH} 8.0$ ) at $4{ }^{\circ} \mathrm{C}$. The stock culture was inoculated into $250 \mathrm{ml}$ Erlenmeyer flasks containing $50 \mathrm{ml}$ of seed medium, which was the same modified Gause's no.1 liquid medium as above, but no agar. The culture was incubated on a rotary shaker $\left(180\right.$ r.p.m.) at $28^{\circ} \mathrm{C}$ for $24 \mathrm{~h}$. Fifty millilitres of the seed culture was transferred to a $5000 \mathrm{ml}$ Erlenmeyer flask containing $1000 \mathrm{ml}$ of the producing medium, which was the same as the seed medium. The fermentation was carried out at $28^{\circ} \mathrm{C}$ for $48 \mathrm{~h}$ on a rotary shaker (180 r.p.m.).
Eighty liters of the fermentation broth was centrifuged at 4500 r.p.m. for $20 \mathrm{~min}$, then, the supernatant was obtained and was extracted twice with 401 of ethyl acetate each time. The organic layer was pooled and concentrated under reduced pressure at $37^{\circ} \mathrm{C}$ to give yellow syrup $(2.3 \mathrm{~g})$. It was then separated by preparative thin layer chromatography on $10 \times 10 \mathrm{~cm}$ plates (silica gel $60 \mathrm{~F}_{254}$, Merck KGaA, Darmstadt, Germany) using $\mathrm{CHCl}_{3}-\mathrm{MeOH}, 65: 35(\mathrm{v} / \mathrm{v})$ as the developing solvent. Under UV $365 \mathrm{~nm}$, bands with light blue fluorescence at $R_{f}=0.35$ were scraped and then eluted with methanol to yield a semipurified sample $(260 \mathrm{mg})$. After dissolved in $1 \mathrm{ml}$ methanol, the sample was filtered through a $0.22 \mu \mathrm{m}$ membrane and was further purified by HPLC on a shim-Pack PRC-ODS column $\left(250 \times 20 \mathrm{~mm}\right.$, Shimadzu Corp., Tokyo, Japan) with $\mathrm{MeOH}-\mathrm{H}_{2} \mathrm{O}$, 55:45 (v/v) at $2 \mathrm{ml} \mathrm{min}^{-1}$. Peak at $\mathrm{R}_{\mathrm{t}}=26 \mathrm{~min}$, showed UV absorbance at 247 and $314 \mathrm{~nm}$ detected by prominence diode array detector (SPD-M20A, Shimadzu), was collected and pooled to yield $10.4 \mathrm{mg}$ of (1) as a white powder.

Compound (1) was soluble in dimethyl sulfoxide (DMSO), $\mathrm{MeOH}$, $\mathrm{CHCl}_{3}$ and pyridine. Its m.p. was $79-80^{\circ} \mathrm{C}$. MW of (1) was found to be 435 by high-resolution ESI-MS, which showed $[\mathrm{M}+\mathrm{H}]^{+}$at $m / z 436.2089$ (calcd 436.2079). The molecular formula was then established as $\mathrm{C}_{21} \mathrm{H}_{29} \mathrm{O}_{7} \mathrm{~N}_{3}$, which has nine degrees of unsaturation. ${ }^{13} \mathrm{C}$-NMR and DEPT spectra of (1) indicated 21 carbon signals could be attributed to three carbonyl carbons, six aromatic carbons and 12 aliphatic carbons including six carbons bonded to nitrogen or oxygen. The UV absorption of (1) at $\lambda_{\max }^{\mathrm{MeOH}} \mathrm{nm}(\varepsilon)$ : 202(29930), 246(6491) and 314(3491) was almost identical with that of isocoumarin compounds, such as Sg17-1-4, PM-94128, Y-05460M-A, bacilosarcins and AI-77-B. The IR spectrum (film) of (1) exhibited absorption bands at 3343, 2956,1668,1620,1539, 1231, 807, $697 \mathrm{~cm}^{-1}$, which indicated the presence of a benzoic acid moiety with a phenolic hydroxyl group and an amide group. All data above revealed (1) had a

\footnotetext{
${ }^{1}$ Department of Microbial Chemistry, Institute of Medicinal Biotechnology, Chinese Academy of Medical Sciences and Peking Union Medical College, Beijing, PR China; ${ }^{2}$ Clinical Microbiology Laboratory, National Center for Clinical Laboratories, Beijing Hospital, Beijing, PR China and ${ }^{3}$ Department of Pharmacology, Medical College of Shantou University, Shantou, PR China

Correspondence: Professor C-H Sun, Department of Microbial Chemistry, Institute of Medicinal Biotechnology, Chinese Academy of Medical Sciences and Peking Union Medical College, Tian Tan Xi Li no.1, Beijing 100050, PR China.

E-mail: chenghangsun@hotmail.com
}

Received 16 September 2012; revised 6 December 2012; accepted 12 December 2012; published online 23 January 2013 
chromophore similar to the 3, 4-dihydro-8-hydroxyisocoumarin skeleton in its structure. NMR data of (1) in DMSO- $d_{6}$ (I) and $\mathrm{CD}_{3} \mathrm{OD}$ (II) were listed in Table 1 . By careful analysis of ${ }^{1} \mathrm{H}$ and ${ }^{13} \mathrm{C}$ NMR, ${ }^{1} \mathrm{H}-{ }^{1} \mathrm{H}$ COSY, DEPT, ${ }^{13} \mathrm{C}-{ }^{1} \mathrm{H}$ COSY, HMBC spectra in DMSO- $d_{6}$ and in $\mathrm{CD}_{3} \mathrm{OD}$ together with NOESY and $\mathrm{D}_{2} \mathrm{O}$ exchange experiment in DMSO- $d_{6}$, chemical structure of (1) was elucidated. It consisted of structural fragment L and R, as shown in Figure 2.<smiles>CC(C)CC(NC(=O)C1NCNC(CC(=O)O)C1O)C1Cc2cccc(O)c2C(=O)O1</smiles>

Structure of PJS (1)

Figure 1 Structure of PJS (1).
Identification of structural fragment $\mathrm{L}$ was started from H-5, H-6 and $\mathrm{H}-7$. The three aromatic protons were readily observed and displayed the coupling patterns for 1,2 , 3-trisubstituted benzenoid ring in ${ }^{1} \mathrm{H}$ NMR. Their corresponding carbons were assigned by ${ }^{13} \mathrm{C}-{ }^{1} \mathrm{H}$ COSY. Other three aromatic carbons were observed and assigned by tracing cross peaks from $\mathrm{H}-5$ and $\mathrm{H}-7$ to $\mathrm{C}-8 \mathrm{a}$, from $\mathrm{H}-6$ to $\mathrm{C}-4 \mathrm{a}$ and $\mathrm{C}-8$ in HMBC. Chemical shift of C-8 at 161.5 suggested a hydroxyl group should attach to C-8, which was confirmed by NOESY correlation from 8 -OH proton at $\delta 7.24$ to $\mathrm{H}-7$ at $\delta 6.82$ in DMSO- $d_{6}$. Identification of isopentyl group in structural fragment L was started from two methyl protons, $\mathrm{H}-1^{\prime}$ at $\delta 0.84$ and $\mathrm{H}-2^{\prime}$ at $\delta 0.89$ in ${ }^{1} \mathrm{H}-\mathrm{NMR}$ in DMSO- $d_{6}$, which showed HMBC correlation to one another, meanwhile, to C- $4^{\prime}$ at $\delta$ 39.1. $\mathrm{H}-1^{\prime}, \mathrm{H}-2^{\prime}$ and $\mathrm{H}-4^{\prime}$ showed cross peaks with a methine proton $\mathrm{H}-3^{\prime}$ at $\delta 1.61$ in ${ }^{1} \mathrm{H}-{ }^{1} \mathrm{H}$ COSY. These observations suggested $3^{\prime}-\mathrm{CH}$ linked with $1^{\prime}-\mathrm{CH}_{3}, 2^{\prime}-\mathrm{CH}_{3}$ and $4^{\prime}-\mathrm{CH}_{2}$. A cross peak observed between $\mathrm{H}-4^{\prime}$ and $\mathrm{H}-5^{\prime}$, a methine proton at $\delta 4.20$ in ${ }^{1} \mathrm{H}-{ }^{1} \mathrm{H}$ COSY confirmed the presence of the isopentyl group. $\mathrm{H}-5^{\prime}$ had a cross peak with $\mathrm{H}-3$, a methine proton at $\delta 4.66$ in ${ }^{1} \mathrm{H}-{ }^{1} \mathrm{H}$ COSY in DMSO- $d_{6}$, in turn, $\mathrm{H}-3$ showed COSY correlation with $\mathrm{H}-4$. $\mathrm{H}-4$ showed $\mathrm{HMBC}$ correlation with C-8a in DMSO- $d_{6}$, meanwhile, H-4 also showed HMBC correlation with $\mathrm{C}-5$ in $\mathrm{CD}_{3} \mathrm{OD}$. Thus, connectivity between $\mathrm{C}-4$ and $\mathrm{C}-4 \mathrm{a}$ was established. Chemical shift of $\mathrm{H}-3$ and its corresponding carbon, C-3 at $\delta 81.0$ in low field indicated C-3 should attach to the oxygen of lactone

Table 1 NMR data of 1 in DMSO- $d_{6}$ (I) and $\mathrm{CD}_{3} \mathrm{OD}$ (II)

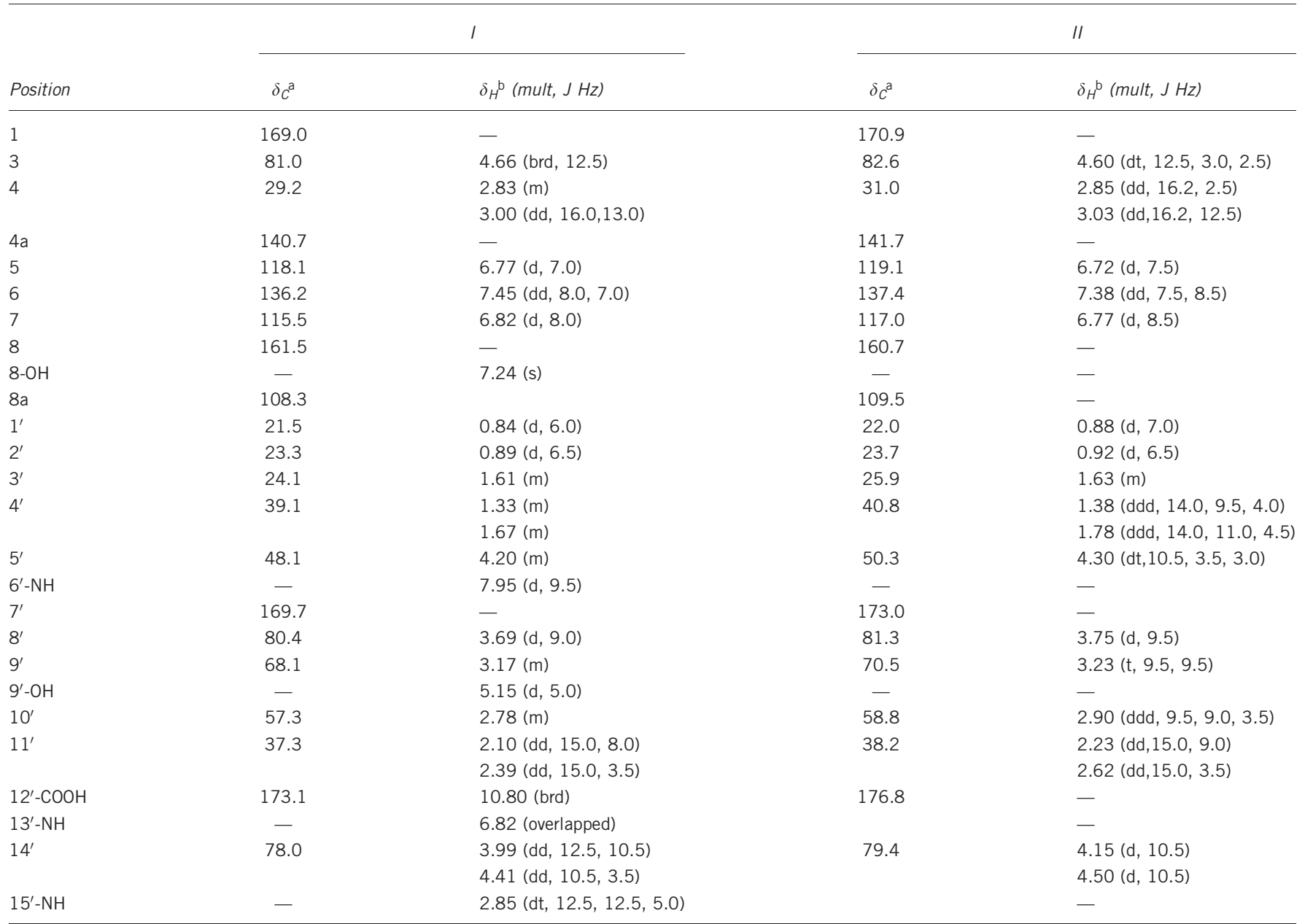

aRecorded at $125 \mathrm{MHz}$

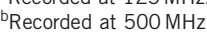


a
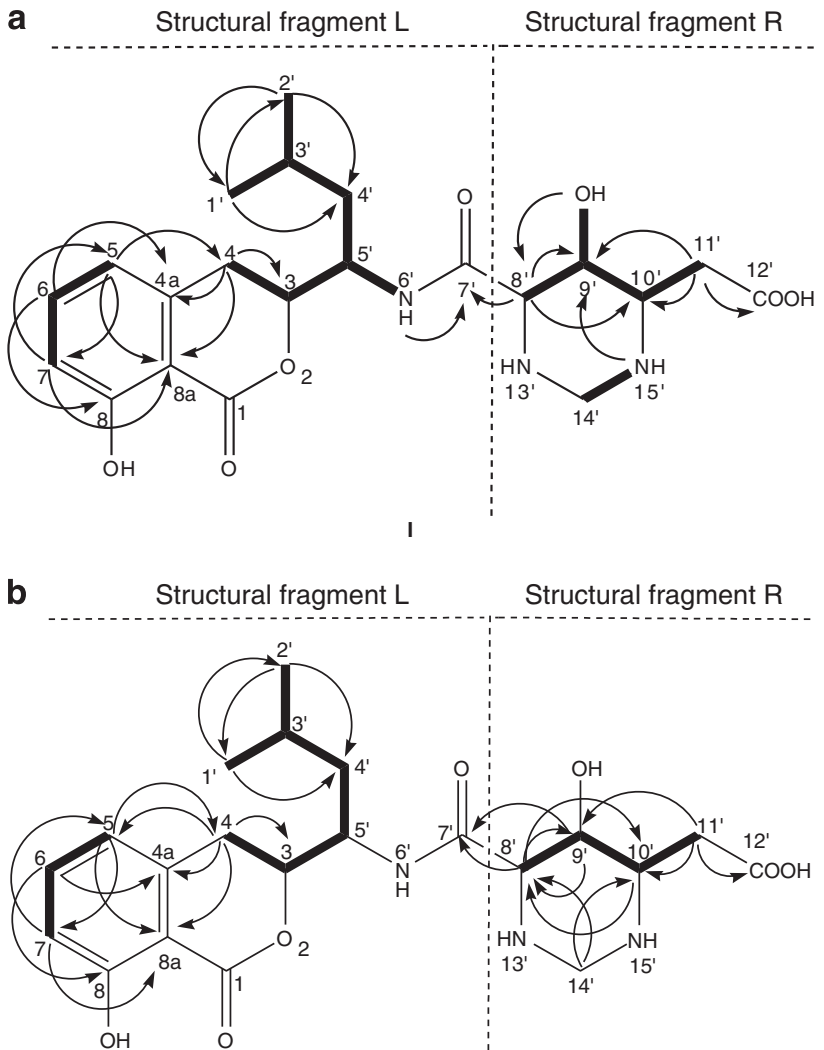

\section{$\mathrm{L}$} Structural fragment $\mathrm{R}$

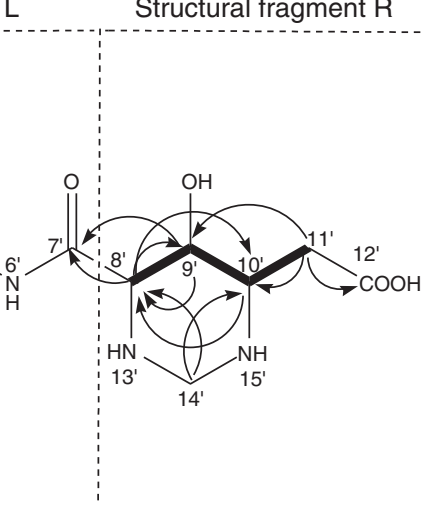

II

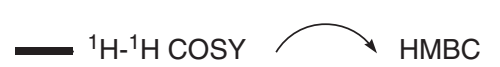

Figure 2 Summary of ${ }^{1} \mathrm{H}^{1} \mathrm{H}$ COSY and $\mathrm{HMBC}$ experiments of (1) in DMSO- $d_{6}(\mathrm{I})$ and $\mathrm{CD}_{3} \mathrm{OD}(\mathrm{II})$.

ring to form 3, 4-dihydro-8-hydroxyisocoumarin skeleton. Furthermore, a cross peak observed between $\mathrm{H}-5^{\prime}$ and $6^{\prime}-\mathrm{XH}$ proton at $\delta 7.95$ in ${ }^{1} \mathrm{H}-$ ${ }^{1} \mathrm{H}$ COSY in DMSO- $d_{6}$ revealed $6^{\prime}-\mathrm{XH}$ bound with $\mathrm{C}-5^{\prime}$ at $\delta$ 48.1. Chemical shift of $\mathrm{H}-5^{\prime}$ and $\mathrm{C}-5^{\prime}$ in downfield, as well as a cross peak observed between $6^{\prime}-\mathrm{XH}$ proton and $7^{\prime}-\mathrm{C}=\mathrm{O}$ at $\delta 169.7$ in $\mathrm{HMBC}$ in DMSO- $d_{6}$ revealed $\mathrm{XH}$ was $\mathrm{NH}$, which bound to $7^{\prime}-\mathrm{C}=\mathrm{O}$ to form an amide group. All data above revealed (1) had methylbutylamino-3, 4dihydro-8-hydroxyisocoumarin, which was the common structural moiety of amicoumacin group of antibiotics. It was further confirmed by comparison of ${ }^{1} \mathrm{H}$ and ${ }^{13} \mathrm{C}-\mathrm{NMR}$ data of (1) with that of known amicoumacin group of compounds such as PM-94128, Y-05460M-A, xenocoumacins and AI-77-B.

In structural fragment $\mathrm{L}$ of (1), there were seven degrees of unsaturation. Thus, two degrees of unsaturation were left in structural fragment R. Elucidation of structural fragment $\mathrm{R}$ was started from $\mathrm{H}-8^{\prime}$, a methine proton, which was readily observed as a doublet signal at $\delta 3.69$ in ${ }^{1} \mathrm{H}-\mathrm{NMR}$ in DMSO- $d_{6}$. By tracing the cross peaks from $\mathrm{H}-8^{\prime}$ to $\mathrm{H}-9^{\prime}$, from $\mathrm{H}-9^{\prime}$ to $\mathrm{H}-10^{\prime}$, from $\mathrm{H}-10^{\prime}$ to $\mathrm{H}-11^{\prime}$ in ${ }^{1} \mathrm{H}-{ }^{1} \mathrm{H}$ COSY, structural moiety as $-\mathrm{CH}\left(8^{\prime}\right)-\mathrm{CH}\left(9^{\prime}\right)-\mathrm{CH}\left(10^{\prime}\right)$ $\mathrm{CH}_{2}\left(11^{\prime}\right)$ - was identified, and was further confirmed by cross peaks in HMBC between $\mathrm{H}-8^{\prime}$ and C-10' between $\mathrm{H}-11^{\prime}$ and $\mathrm{C}^{\prime} 9^{\prime}$ in DMSO$d_{6}$, in addition, between $\mathrm{H}-10^{\prime}$ and $\mathrm{C}-8^{\prime}$ in $\mathrm{CD}_{3} \mathrm{OD}$. A broad single signal in downfield at $\delta 10.8$ in ${ }^{1} \mathrm{H}-\mathrm{NMR}$ and a quaternary carbon signal in downfield at $\delta 173.1$ in ${ }^{13} \mathrm{C}-\mathrm{NMR}$ in DMSO- $d_{6}$ suggested the presence of $12^{\prime}$-COOH. A cross peak observed between $\mathrm{H}-11^{\prime}$ and $\mathrm{C}-12^{\prime}$ in HMBC suggested $12^{\prime}-\mathrm{COOH}$ was attached to $\mathrm{C}-11^{\prime}$.
Table 2 Antimicrobial activity of PJS

\begin{tabular}{lc}
\hline Test organisms & MIC $\left(\mu \mathrm{g} \mathrm{m} \mathbf{I}^{-1}\right)$ \\
\hline Staphylococcus aureus ATCC 25923 & 1 \\
Oxacillin-resistant Staphylococcus aureus (ORSA) & 2 \\
Oxacillin-resistant Staphylococcus epidermidis (ORSE) & 1 \\
Enterococcus faecalis ATCC 29212 & 64 \\
Enterococcus faecalis ATCC 33186 & 128 \\
Bacillus subtilis ATCC 6633 & 64 \\
Micrococcus luteus FDA 1001 & 0.25 \\
Streptococcus pneumoniae CMCC 31001 & 0.5 \\
Escherichia coli ATCC 25922 & 64 \\
Pseudomonas aeruginosa ATCC 27853 & $>128$ \\
Salmonella enteritidis CMCC 50041 & 128 \\
Klebsiella pneumoniae ATCC 700603 & $>128$ \\
Shigella flexneri CMCC 51571 & 2 \\
Acinetobacter baumannii 2799 & $>128$ \\
Candida parapsilosis ATCC 22019 & 128 \\
Candida albicans CCTCC AY 93025 & 128 \\
Candida tropicalis CCTCC AY 93006 & $>128$ \\
Penicillium marneffei FRR 2161 & $>128$ \\
\hline
\end{tabular}

On the basis of chemical shift of $\mathrm{H}-9^{\prime}$ at 3.17 , C- $9^{\prime}$ at 68.1 and $\mathrm{H}-10^{\prime}$ at $2.78, \mathrm{C}-10^{\prime}$ at 57.3 in DMSO- $d_{6}$, it was speculated that a hydroxyl group attached to $\mathrm{C}-9^{\prime}$ and a $\mathrm{NH}$ attached to $\mathrm{C}-10^{\prime}$. It was confirmed by $\mathrm{D}_{2} \mathrm{O}$ exchange experiment. When drops of $\mathrm{D}_{2} \mathrm{O}$ added into DMSO- $d_{6}$, a proton at $\delta 5.15(\mathrm{~d}, J=5.0)$, showed COSY correlation with $\mathrm{H}-9^{\prime}$ and $\mathrm{HMBC}$ correlation with $\mathrm{C}-8^{\prime}$ in DMSO$d_{6}$, was absent. Thus, the proton was attributed to $9^{\prime}-\mathrm{OH}$. Meanwhile, another proton at $\delta 2.85(\mathrm{dt}, J=12.5,12.5,5.0)$, showed COSY correlation to $\mathrm{H}-14^{\prime}$ and $\mathrm{HMBC}$ correlation to C- $9^{\prime}$ in DMSO- $d_{6}$, was also absent. Thus, the proton was attributed to $15^{\prime}-\mathrm{NH}$. The absence of $15^{\prime}-\mathrm{NH}$ proton in $\mathrm{D}_{2} \mathrm{O}$ exchange experiment led the multiplicity of $\mathrm{H}-10^{\prime}$ at $\delta 2.78(\mathrm{~m}), \mathrm{H}-14^{\prime}$ at $\delta 3.99(\mathrm{dd}, J=10.5,12.5)$ and $\delta 4.41$ $(\mathrm{dd}, J=10.5,3.5)$ simplified as the corresponding data in ${ }^{1} \mathrm{H}-\mathrm{NMR}$ in $\mathrm{CD}_{3} \mathrm{OD}$. The phenomena suggested that $15^{\prime}-\mathrm{NH}$ not only attached to C-14', but also attached to C-10'. By the calculation of element composition and degrees of unsaturation of (1), it was speculated that a hexahydropyrimidine ring must exist in structural fragment $\mathrm{R}$ and was composed of $8^{\prime}-\mathrm{CH}, 9^{\prime}-\mathrm{CH}, 10^{\prime}-\mathrm{CH}, 15^{\prime}-\mathrm{NH}, 14^{\prime}-\mathrm{CH}_{2}$, and left $13^{\prime}-\mathrm{NH}$ at $\delta 6.82$ overlapped by the aromatic proton of $\mathrm{H}-7$. Cross peaks between $\mathrm{H}-14^{\prime}$ and $\mathrm{C}-8^{\prime}$, between $\mathrm{H}-14^{\prime}$ and $\mathrm{C}-10^{\prime}$ in HMBC spectrum in $\mathrm{CD}_{3} \mathrm{OD}$ further supported the speculation. Thus, the structural fragment $\mathrm{R}$ was elucidated.

$\mathrm{HMBC}$ correlations from $\mathrm{H}-9^{\prime}$ to $\mathrm{C}^{-7^{\prime}}$ in $\mathrm{CD}_{3} \mathrm{OD}$ revealed the linkage between the structural fragment $\mathrm{L}$ and structural fragment $\mathrm{R}$ was through $\mathrm{C}-8^{\prime}$ to $\mathrm{C}-7^{\prime}$ and completed the elucidation of the planar chemical structure of (1), which was further confirmed by downfield shift of $13^{\prime}-\mathrm{NH}$ proton, which could form $\mathrm{H}$-bonding with $7^{\prime}-\mathrm{C}=\mathrm{O}$.

By analysis of ${ }^{1} \mathrm{H}-{ }^{1} \mathrm{H}$ coupling constants and cross peaks observation in NOESY, the relative configuration of $\mathrm{H}-3, \mathrm{H}-8^{\prime}, \mathrm{H}-9^{\prime}, \mathrm{H}-10^{\prime}$ and $\mathrm{H}-15^{\prime}$ were elucidated. In the ${ }^{1} \mathrm{H}-\mathrm{NMR}$ in $\mathrm{CD}_{3} \mathrm{OD}$, large diaxial coupling constants between $\mathrm{H}-3$ and $\mathrm{H}-4$, between $\mathrm{H}-8^{\prime}$ and $\mathrm{H}-9^{\prime}$, between $\mathrm{H}-9^{\prime}$ and $\mathrm{H}-10^{\prime}$ were observed as $12.5,9.5$ and $9.5 \mathrm{~Hz}$, separatively, which indicated all protons including $\mathrm{H}-3, \mathrm{H}-8^{\prime}, \mathrm{H}-9^{\prime}$, $\mathrm{H}-10^{\prime}$ had axial orientation. In the ${ }^{1} \mathrm{H}-\mathrm{NMR}$ in DMSO- $d_{6}$, two large diaxial coupling constants between $\mathrm{H}-10^{\prime}$ and $\mathrm{H}-15^{\prime}$, between $\mathrm{H}-14^{\prime}$ and $\mathrm{H}-15^{\prime}$ were observed as 12.5 and $12.5 \mathrm{~Hz}$, respectively. It indicated $\mathrm{H}-15^{\prime}$ also had axial orientation. As for $\mathrm{H}-13^{\prime}$ overlapped by $\mathrm{H}-7$, careful analysis of its vicinal protons in DMSO- $d_{6}$ in ${ }^{1} \mathrm{H}-\mathrm{NMR}$ 
showed $\mathrm{H}-13^{\prime}$ had no contribution to multiplicity and coupling constants of $\mathrm{H}-8^{\prime}$ and $\mathrm{H}-14^{\prime}$. In addition, no cross peak can be observed between $\mathrm{H}-13^{\prime}$ and $\mathrm{H}-8^{\prime}$ or $\mathrm{H}-14^{\prime}$ in NOESY in DMSO- $d_{6}$. Therefore, $\mathrm{H}-13^{\prime}$ either had an equatorial orientation or couldn't be defined, due to rapid interchange in DMSO- $d_{6}$.

PJS was active against Gram-positive and less active against Gramnegative bacteria and fungi. MICs were determined by broth microdilution method according to National Committee for Clinical Laboratory Standards guidelines. ${ }^{10,11}$ The MIC values of PJS were listed in Table 2. The cytotoxicities in vitro against murine leukaemia P388 cells, human lung adenocarcinoma epithelial cell lines A549, human liver hepatocellular carcinoma cell lines HepG2, human pancreatic adenocarcinoma cell lines SW1990, human cervical cancer HeLa cells were measured by the methylthiazolyldiphenyl-tetrazolium bromide (MTT) assay. ${ }^{12}$ PJS exhibited activities with $\mathrm{IC}_{50}$ values of 103.6, 70.7, 39.5, 34.2, and $4.0 \mu \mathrm{M}$, separatively.

\section{ACKNOWLEDGEMENTS}

Financial supports from the National Natural Sciences Foundation of China (NSFC, Grant no.81172963), the National Science and Technology Major Project (Grant no.2012ZX09301-002-001-018, -003, -014) from the Ministry of Science and Technology of China, Specialized Research Fund for the Doctoral Programme of Higher Education from the Ministry of Education of China (SRFDP, Grant no. 20111106110032) and IMB grant (IMBF201204) are gratefully acknowledged.
1 Okazaki, H., Kishi, T., Beppu, T. \& Arima, K. A new antibiotic, baciphelacin. J. Antibiot. 28, 717-719 (1975).

2 Itoh, J., Omoto, S., Nishizawa, N., Kodama, Y. \& Inouye, S. Chemical structures of amicoumacins produced by Bacillus pumilus. Agric. Biol. Chem. 46, 2659-2665 (1982).

3 Shimojima, Y., Hayashi, H., Ooka, T., Shibukawa, M. \& litaka, Y. Studies on Al-77s, microbial products with gastroprotective activity. structures and the chemical nature of Al-77s. Tetrahedron 40, 2519-2527 (1984)

4 McInerney, B. V., Taylor, W. C., Lacey, M. J., Akhurst, R. J. \& Gregson, R. P. Biologically acitive metabolites from Xenorhabdus spp., part 2. Benzopyran-1-one derivatives with gastroprotective activity. J. Nat. Prod. 54, 785-795 (1991).

5 Sato, T. et al. A new isocoumarin antibiotic, Y-05460M-A. J. Antibiot. 45, 1949-1952 (1992).

6 Cañedo, L. M. et al. PM-94128, a new isocoumarin antitumor agent produced by a marine bacterium. J. Antibiot. 50, 175-176 (1997).

7 Huang, Y. F. et al. Sg17-1-4, a novel isocoumarin from a marine fungus Alternaria tenuis Sg17-1. J. Antibiot. 59, 355-357 (2006).

8 Azumi, M. et al. Bacilosarcins A and B, novel bioactive isocoumarins with unusual heterocyclic cores from the marine-derived bacterium Bacillus subtilis. Tetrahedron 64, 6420-6425 (2008).

$9 \mathrm{Li}, \mathrm{Y}$. X. et al. Five new amicoumacins isolated from a marine-derived bacterium Bacillus subtilis. Mar. Drugs 10, 319-328 (2012).

10 National Committee for Clinical Laboratory Standards. Methods for dilution antimicrobial susceptibility tests for bacteria that grow aerobically. Approved standard, 9th ed. NCCLS document M7-A9. National Committee for Clinical Laboratory Standards (2012).

11 National Committee for Clinical Laboratory Standards. Reference method for Broth Dilution Antifungal Susceptibility Testing of Yeasts. Approved standard, 3th ed. NCCLS document M27-A3. National Committee for Clinical Laboratory Standards (2012).

12 Hazalin, N. A. et al. Cytotoxic and antibacterial activities of endophytic fungi isolated from plants at the National Park, Pahang, Malaysia. BMC Complement. Altern. Med. 9, 46-50 (2009). 